удК 343.85

\author{
С. А. Корягина \\ Байкальский государственный университет, \\ г. Иркутск, Российская Федераиия \\ И. В. Лавыгина \\ Байкальский государственный университет, \\ г. Иркутск, Российская Федераиия
}

\title{
СОВРЕМЕННЫЕ ТЕНДЕНЦИИ НАЗНАЧЕНИЯ НЕКОТОРЫХ ВИДОВ НАКАЗАНИЙ ОСУЖДДЕННЫМ В РОССИЙСКОЙ ФЕДЕРАЦИИ
}

\begin{abstract}
АНнотАЦия. В статье дается описание назначения некоторых видов наказаний осужденным лицам, связанных с изоляцией от общества, такие как, лишение свободы на определенный срок, пожизненное лишение свободы, так и не связанные с лишением свободы штраф, обязательные работы, исправительные работы, ограничение свободы. Отмечаются недостатки, препятствующие полноценной реализации альтернатив лишению свободы. Более того, дается правовой анализ измененному наказанию в виде ограничения свободы, который близок, по мнению авторов, по своему содержанию к условному осуждению, но при этом не содержит особых затруднений в своем практическом применении. Вместе с этим отмечается и условное осуждение к лишению свободы как меры уголовно-правового характера. Анализируется с учетом последних изменений действующего уголовного законодательства, такие виды наказаний как штраф, лишение специального, воинского или почетного звания, классного чина и государственных наград, принудительные работы.

ключевЫЕ словА. Российская Федерация; назначение наказания; лишение свободы; условное осуждение; принудительные работы; осужденные лица; уголовный кодекс.

ИНФОРМАЦИЯ О СТАТЬЕ. Дата Поступления 1 июня 2017 г.; дата принятия к печати 11 октября 2017 г.; дата онлайн-размещения 25 октября 2017 г.
\end{abstract}

\section{S. A. Koryagina Baikal State University, Irkutsk, Russian Federation \\ I. V. Lavygina Baikal State University, Irkutsk, Russian Federation}

\section{CURRENT TRENDS IN THE ASSIGNMENT OF CERTAIN TYPES OF SENTENCES CONVICTED PERSONS IN THE RUSSIAN FEDERATION}

\begin{abstract}
The article gives a description of the purpose of certain types of penalties on the convicted persons related to isolation from society, such as imprisonment for certain term, lifelong imprisonment and non-custodial penalty, obligatory works, corrective works, restriction of freedom. Shortcomings that prevent the full implementation of alternatives to deprivation of liberty. Moreover, it provides a legal analysis of the amended penalty of restriction of liberty, which is close, according to the authors, according to their contents, to probation, but it does not contain any particular difficulties in its practical application. Along with this it is noted and probation to imprisonment as measures of criminal-legal nature. Is analyzed taking into account the recent changes of the current criminal legislation, such types of punishment as a fine, deprivation of special, military or honorary title, class rank and state awards, compulsory labour.

KEYWORDS. Russian Federation; sentencing; imprisonment; probation; forced labor; convicts of the penal code.

ARTICLE INFO. Received June 1, 2017; accepted October 11, 2017; available online October 25, 2017.
\end{abstract}

\section{Baikal Research Journal}


«Рационализация политики в области уголовного наказания предполагает увеличение к 2020 году общей численности лиц, осужденных к наказаниям, не связанным с изоляцией осужденного от общества, на 200 тыс. человек за счет применения ограничения свободы и других видов наказаний, увеличения количества санкций, предусматривающих наказания, не связанные с изоляцией от общества, и расширения практики назначения данных наказаний судами» ${ }^{1}-$ современная тенденция уголовно-правовой политики, определяемая принципами гуманизма и справедливости.

Иными словами можно сказать, что в настоящее время идет активный поиск путей сокращения применения реального лишения свободы посредством введения наказаний и иных мер уголовно-правового характера без изоляции от общества.

Представляется, что главной идеей экономии репрессии является адекватность назначенного наказания за совершенное деяние. Государственный подход должен заключаться в возможности применения альтернативных мер наказанию лишению свободы и возможности исключения направления в исправительные учреждения лиц, исправление которых возможно без его отбывания. В постановлении пленума Верховного Суда Российской Федерации, отмечалось, обратить внимание судов, на необходимость исполнения требований закона о строго индивидуальном подходе к назначению наказания, т.е. учитывать соразмерность характера и степени общественной опасности преступления, обстоятельства его совершения и личности виновного» ${ }^{2}$.

Следует заметить, что «уголовное законодательство Российской Федерации содержит большее количество наказаний по сравнению с законодательством других стран, например, в (США, Англии, Германии). Отмечается, «что включает в свое законодательство, два-четыре видов наказания, такие, как лишения свободы, штраф, смертная казнь (где она не отменена)» [1]. В ст. 44 УК РФ регламентировано тринадцать видов уголовных наказаний, из которых в правоприменительной практике используется пять-семь» [2].

Анализируя практику назначения наказания осужденным лицам в России, можно сказать, что реально применяется только шесть: штраф, обязательные работы, исправительные работы, ограничение свободы, лишение свободы на определенный срок, пожизненное лишение свободы.

Следует отметить, что такой вид наказания, как ограничение свободы в Российской Федерации стал назначаться осужденным лицам только с 2010 г. и имеет устойчивую тенденцию к росту в 2015 году, его удельный вес составляет $3,0 \%$, по сравнению с базовым 2010 годом. Пределы и условия его правоприменения предусмотрены в ст. 53 УК РФ. Вместе с этим, в юридической литературе встречается мнение, что наказание в виде ограничения свободы и условное осуждение как самостоятельный институт уголовного права имеют некоторое сходство [3]. Представляется, что ограничение свободы является самостоятельным видом наказания предусмотренное ст. 44 УК РФ, а условное осуждение не входит в перечень видов наказаний ст. 44 УК РФ.

Кроме того, обращает на себя внимание и то обстоятельство, что доля назначаемых наказаний, не связанных с изоляцией от общества, в общей структуре на-

${ }^{1}$ Концепции развития уголовно-исполнительной системы Российской Федерации до 2020 года. № 1772-p. URL: http://docs.cntd.ru.

${ }^{2}$ O практике назначения судами Российской Федерации уголовного наказания : постановление Пленума Верховного Суда РФ от 12.12.2015 г. № 58. URL: http://www.consultant.ru.

\section{Baikal Research Journal}

электронный научный журнал Байкальского государственного университета 
значенных наказаний осужденным лицам имеют устойчивую тенденцию к росту в 2015 г. по сравнению с 2010 г. (табл.) $)^{3}$.

\section{Назначение некоторых видов наказаний, осужденным лищам в Российской Федеращии (2008-2015 г2.), в \%}

\begin{tabular}{|c|c|c|c|c|c|c|c|c|}
\hline \multirow{2}{*}{ Вид наказания } & \multicolumn{8}{|c|}{ Российская Федерация } \\
\hline & 2008 & 2009 & 2010 & 2011 & 2012 & 2013 & 2014 & 2015 \\
\hline Всего осуждено & 925166 & 892360 & 845071 & 782274 & 739278 & 735340 & 719305 & 728082 \\
\hline $\begin{array}{l}\text { из них: } \\
\text { освобождено от нака- } \\
\text { зания по амнистии и } \\
\text { другим основаниям }\end{array}$ & 3307 & 2885 & 3345 & 3356 & 3827 & 4613 & 6879 & 99726 \\
\hline $\begin{array}{l}\text { Осуждено к видам } \\
\text { наказания }\end{array}$ & 921859 & 889475 & 841726 & 778918 & 735451 & 730727 & 712496 & 628356 \\
\hline $\begin{array}{l}\text { в том числе к: } \\
\text { пожизненному лише- } \\
\text { нию свободы }\end{array}$ & 67 & 73 & 66 & 64 & 66 & 67 & 68 & 70 \\
\hline $\begin{array}{l}\text { Удельный вес в общем } \\
\text { числе осужденных к } \\
\text { мерам наказания, в \% }\end{array}$ & 0,007 & 0,008 & 0,007 & 0,008 & 0,008 & 0,009 & 0,009 & 0,011 \\
\hline $\begin{array}{l}\text { реальному лишению } \\
\text { свободы на определен- } \\
\text { ный срок }\end{array}$ & 312137 & 289202 & 265843 & 227050 & 206254 & 209728 & 209448 & 220448 \\
\hline $\begin{array}{l}\text { Удельный вес в общем } \\
\text { числе осужденных к } \\
\text { мерам наказания, в \% }\end{array}$ & 33,9 & 32,5 & 31,6 & 29,1 & 28,0 & 28,7 & 29,4 & 29,0 \\
\hline $\begin{array}{l}\text { условное осуждение к } \\
\text { лишению свободы }\end{array}$ & 356696 & 341514 & 307206 & 282227 & 221908 & 201538 & 197859 & 172925 \\
\hline $\begin{array}{l}\text { Удельный вес в общем } \\
\text { числе осужденных к } \\
\text { мерам наказания, в \% }\end{array}$ & 38,9 & 38,4 & 36,5 & 36,2 & 30,2 & 27,6 & 27,8 & 23,0 \\
\hline Ограничению свободы & 0 & 0 & 7941 & 10994 & 25269 & 32042 & 26983 & 21461 \\
\hline $\begin{array}{l}\text { Удельный вес в общем } \\
\text { числе осужденных к } \\
\text { мерам наказания, в \% }\end{array}$ & 0 & 0 & 0,9 & 1,4 & 3,4 & 4,4 & 3,8 & 3,0 \\
\hline Обязательные работы & 49317 & 19628 & 79874 & 89881 & 76560 & 73172 & 69898 & 77548 \\
\hline $\begin{array}{l}\text { Удельный вес в общем } \\
\text { числе осужденных к } \\
\text { мерам наказания, в \% }\end{array}$ & 5,3 & 2,2 & 9,5 & 11,5 & 10,4 & 10,0 & 9,8 & 10,2 \\
\hline $\begin{array}{l}\text { Исправительные } \\
\text { работы }\end{array}$ & 47892 & 44398 & 41282 & 40037 & 70400 & 75778 & 75120 & 64401 \\
\hline $\begin{array}{l}\text { Удельный вес в общем } \\
\text { числе осужденных к } \\
\text { мерам наказания, в \% }\end{array}$ & 5,2 & 5,0 & 4,9 & 5,1 & 9,6 & 10,4 & 10,5 & 10,1 \\
\hline Штраф & 133772 & 131402 & 123495 & 113503 & 113358 & 116176 & 111842 & 89431 \\
\hline $\begin{array}{l}\text { Удельный вес в общем } \\
\text { числе осужденных к } \\
\text { мерам наказания, в \% }\end{array}$ & 14,5 & 14,8 & 14,7 & 14,6 & 15,4 & 15,9 & 15,7 & 11,7 \\
\hline $\begin{array}{l}\text { Другим видам нака- } \\
\text { зания }\end{array}$ & 19978 & 63258 & 16019 & 15162 & 21636 & 22226 & 21208 & 20155 \\
\hline
\end{tabular}

${ }^{3}$ Данные Управления Судебного департамента при Верховном Суде РФ за 2015 г. URL: http:// www.cdep.ru. ; Основные статистические показатели состояния судимости в России за 2008-2014 годы. URL: http://www.cdep.ru.

\section{Baikal Research Journal}


Окончание таблицы

\begin{tabular}{|l|r|r|r|r|r|r|r|r|}
\hline \multirow{2}{*}{ Вид наказания } & \multicolumn{7}{|c|}{ Российская Федерация } \\
\cline { 1 - 9 } & \multicolumn{1}{|c|}{2008} & \multicolumn{1}{c|}{2009} & 2010 & \multicolumn{1}{c|}{2011} & \multicolumn{1}{c|}{2012} & \multicolumn{1}{c|}{2014} & 2015 \\
\hline $\begin{array}{l}\text { Удельный вес в общем } \\
\text { числе осужденных к } \\
\text { мерам наказания, в \% }\end{array}$ & 2,2 & 7,1 & 1,9 & 1,9 & 2,9 & 3,0 & 3,0 & 3,0 \\
\hline
\end{tabular}

Наибольший удельный вес в общей структуре назначаемых наказаний осужденным лицам за восемь лет в России имеет лишение свободы на определенный срок (табл.). Наблюдается снижение удельного веса этого вида наказания осужденным в 1,2 раза в 2015 г. $(29,0 \%)$ по сравнению с 2008 г. (33,9 \%), т.е. на $4,9 \%$. Однако, отмечается, что лишение свободы на определенный срок продолжает составлять основную долю в структуре назначенных наказаний осужденным лицам. Вместе с тем, анализ статистических данных свидетельствует, что в большинстве случаев судами принимается решение о применении условного осуждения к таким подсудимым и лишение свободы им назначается условно в среднем в 30 \% случаев. Подобного воздействия, конечно, недостаточно для лиц, совершивших тяжкие преступления. Однако для достижения целей наказания в отношении преступников, совершивших менее опасные преступления, нередко можно ограничиться тем карательным воздействием, которое оказывает сам факт назначения наказания. Поскольку репрессивный потенциал условного осуждения гораздо меньше, чем наказания, но это не позволяет говорить о том, что и степень эффективности условного осуждения меньше, чем у наказания. Условное осуждение оказывает принудительно-воспитательное воздействие на осужденного. При применении условного осуждения суд должен учитывать требования общих начал назначения наказаний, порядок и пределы применения условного осуждения, исходить из целей уголовного наказания. Иными словами, необходимо исправить осужденного и предупредить совершения преступлений [4].

Вместе с тем, данные таблицы свидетельствуют, что следующим видом наказания по величине удельного веса является штраф. Анализируя практику его назначения, следует отметить, что за исследуемый период его удельный вес, в среднем составляет 14,5\%, однако в 2014 г. наблюдается снижение данного показателя на $3 \%$ по сравнению с базовым 2008 годом, в структуре всех видов назначаемых наказаний осужденным лицам.

Представляется, что штраф является эффективным видом наказания, обладает меньшей степенью репрессивности. Поскольку не ограничивает свободу передвижения осужденного, его желания менять место жительства, или место работы. Иными словами, назначение штрафа как вида уголовного наказания, влечет за собой ущемление только материального положения осужденного и наличие судимости как правового последствия назначенного судом уголовного наказания за совершенное общественно опасное деяние.

Кроме этого отмечается, положительная динамика назначения наказаний обязательных и исправительных работ в общей структуре назначаемых наказаний осужденным лицам. Так, в 2014 г. указанные виды наказаний были назначены каждому десятому осужденному. Содержание этих видов наказания заключается в выполнении осужденным трудовых обязанностей, вид и объекты, осуществления которых определяются органами местного самоуправления по согласованию с уголовно-исполнительными инспекциями. Исправительные работы характеризуются не только тем, что осужденный претерпевает ограничения материального порядка, а тем, что на осужденного в процессе исполнения наказания оказывается исправительно-трудовое воздействие [5]. Несмотря на незначительную положи-

\section{Baikal Research Journal}

электронный научный журнал Байкальского государственного университета 
тельную динамику назначения обязательных и исправительных работ, проблема неприменения судами рассматриваемых видов наказаний связана с отсутствием гарантий трудоустройства осужденного.

Обращает на себя внимание, и тот факт, что арест, предусмотренный в ст. 44 УК РФ, в настоящее время не применяется, поскольку не созданы необходимые условия для его исполнения. Срок введения в действие принудительных работ обозначен 01.01.2017 г., поэтому в настоящее время говорить об эффективности данного наказания еще преждевременно. Необходимо отметить, что прототипом принудительных работ является распространенный вариант исполнения наказания в Советском Союзе, получивший в быту наименования «химия» [6 с. 156].

Так, в частности, арест был установлен как вид наказания в 1996 г. На момент введения в действия Уголовного Кодекса РФ в Федеральном законе «О введении в действие УК РФ» в ст. 4 в ее первой редакции указывалось, что новые виды наказаний будут вступать в действие по мере создания необходимых условий для их исполнения, но не позднее 2001 г. Затем срок введения ареста был отложен до 2006 г. Парадокс российской системы наказания заключается в том, что данный вид наказания и в настоящее время остается лишь теоретическим конструктом. Двадцать лет существования «на бумаге» без практического применения - это нонсенс правовой системы.

Понятно, что установление ареста в сфере реализации задачи расширения системы наказания, и повышения авторитета уголовного закона в части соответствия мировым стандартам, в упомянутом 1996 г. было политически обосновано и необходимо. Однако практическая несостоятельность данного решения очевидна была уже на этапе принятия этого закона. И если в первом десятилетии применения УК РФ 1996 г. законодатель еще пытался отслеживать его исполнение, продлевая сроки отсрочки введения ареста, то последнее десятилетие выглядит как полное забвение этой проблемы.

Арест - очень дискуссионный вид наказания, даже не имея практического воплощения, он вызывает бурный спор в научном мире по вопросу целесообразности его наличия [7], имея своих сторонников [8] и противников [9], каждый из которых апеллирует стройной системой аргументов, вызывающих интерес и имеющих право на существование.

Учитывая, что введение в действие ареста не имеет ни материально-организационной составляющей, ни теоретической обоснованности (не предусмотрено даже в ближайших планах по реформированию уголовно-исполнительной системы) и за двадцатилетний период никаких подвижек в решении указанного вопроса не наметилось.

В 2011 г. законодатель ввел в систему наказаний новый вид - принудительные работы. Однако в том виде, в котором они сейчас предусмотрены в УК РФ, это нововведение вряд ли способно качественно изменить ситуацию практики применения наказаний в РФ.

Законодатель уже имел негативный опыт включения этого наказания в систему наказаний. Действительно, еще в 1996 г. исправительные работы, только тогда под другим названием (ограничение свободы) были предусмотрены в УК РФ. Столкнувшись со всеми проблемами введения его в действие и признав невозможность такового, было принято решение об отказе от этого наказания. Таким образом, появилось полностью измененное наказание в виде ограничения свободы, очень близкое по своему содержанию к условному осуждению, но при этом не содержащее особых сложностей в своем практическом применении.

$\mathrm{C}$ введением принудительных работ все проблемы практической реализации этого наказания вновь стали актуальны. Таким образом, происходит лишь изме-

\section{Baikal Research Journal}

электронный научный журнал Байкальского государственного университета 
нение названий наказаний, без изменения содержания. То наказание, которое в первоначальном варианте называлось «ограничение свободы», теперь имеет название «принудительные работы». Поэтому все так же остро стоят вопросы финансирования строительства исправительных центров, организации их работы, обеспечения трудовой деятельностью и т.д. Научный мир уже на протяжении длительного времени активно обсуждает проблемы применения наказания в виде принудительных работ [10], которые очевидны даже на этапе теоретического осмысления, острота полемики при этом с годами не ослабевает [11], однако законодатель никаким образом на это не реагирует.

Слабая теоретическая разработанность положений, регламентирующих содержание принудительных работ, требует пристального внимания. Прежде всего, открытым остается вопрос о самостоятельности данного наказания. С одной стороны, оно включено в систему наказаний на общих основаниях как самостоятельный вид наказания, присутствует в санкциях статей Особенной части УК РФ; но при этом, в ст. 53№ УК РФ подчеркивается, что принудительные работы применяются лишь как альтернатива лишению свободы и имеют особый порядок назначения - по сути вторичный. Предусмотрено, что сначала в нарушение положений ст. 60 УК РФ, (где указано, что более строгий вид наказания из числа предусмотренных санкцией, назначается только в том случае, если менее строгий не может обеспечить достижения целей наказания) суд назначает лишение свободы - т.е. уже переходит на более строгий вид наказания из числа предусмотренных санкцией, считая, что все более мягкие виды наказаний не обеспечат достижение целей. Затем, суд, противореча своему первоначальному выводу, должен признать, что исправление осужденного к лишению свободы возможно без реального отбытия назначенного ему наказания, и тогда заменяет лишение свободы на более мягкий вид наказания - принудительные работы. Целесообразность применения такого сложного и достаточно противоречивого способа назначения наказания вызывает много вопросов [12].

Более того, достаточно интересным представляется подход законодателя к определению меры ответственности женщин, имеющих малолетних детей. Фактически получается, что факт наличия ребенка значительно ухудшает положение женщины по сравнению с мужчиной, имеющего такого же возраста ребенка и женщиной, не имеющей детей, либо, имеющей детей старшего возраста. Ведь в УК РФ предусмотрено, что назначать наказание в виде обязательных работ, исправительных работ, принудительных работ запрещено в отношении женщины, имеющей ребенка в возрасте до 3 лет, и арест в отношении женщины, имеющей детей в возрасте до четырнадцати лет. Система наказаний в отношении женщины с таким ребенком выглядит крайне усеченно. По общему правилу человек, совершивший преступление небольшой или средней тяжести, может рассчитывать на применение к нему наказаний, не связанных с лишением свободы, и выбор таких наказаний в законе представлен. Однако женщине с ребенком в возрасте до трех лет в этом отказано. Ведь назначить штраф, как правило, затруднительно в силу учета имущественного положения этой женщины (на которое суды зачастую вынуждены закрывать глаза, чтобы не ухудшить ее положение). Применить наказание в виде лишения права занимать определенную должность или заниматься определенной деятельностью в данном случае невозможно. Обязательные работы, исправительные работы к таким женщинам не применяются. Таким образом, получается, что единственное наказание, которое, по мнению законодателя, должно быть применено к этой женщине - это ограничение свободы. Учитывая то, что принудительные работы или арест к женщине с ребенком в возрасте до 3 лет тоже не применяется, система наказаний в отношении данной категории лиц, совер-

\section{Baikal Research Journal}

электронный научный журнал Байкальского государственного университета 
шивших преступления представлена в виде двух наказаний - это ограничение свободы или лишение свободы (в случае хорошего материального положения может быть применен еще штраф, но, как показывает статистика, в нашей стране слишком высок процент малоимущих лиц). Не смотря на то, что наказание в виде ограничения свободы не мешает полноценно воспитывать женщине своих детей (в отличие от лишения свободы, которое полностью исключает участие матери в воспитании) - это слишком суровое наказание, относящееся по характеру карательных свойств к наказаниям, связанным с лишением или ограничением свободы. Таким образом, создан законодательный вакуум, вынуждающий суды назначать наказание в виде штрафа (даже в том случае, если нет к этому оснований), либо освобождать эту женщину от уголовной ответственности или наказания, либо применять условное осуждение. Сам же факт, что система наказаний в отношении женщины, имеющей ребенка в возрасте до трех лет, столь скудна (два - три наказания), не может свидетельствовать о соответствии ее принципам уголовного права и международным стандартам. В действительно цивилизованном государстве, думается, факт наличия малолетнего ребенка должен быть учтен в системе наказания в диаметрально противоположном направлении.

Еще одним неоднозначным решением законодателя является включение в систему наказаний лишения специального, воинского или почетного звания, классного чина и государственных наград. С одной стороны, действительно, факт совершения тяжкого или особо тяжкого преступления в определенных случаях может не соответствовать, не согласовываться с наличием данного звания, чина или награды. Но, с другой стороны, налицо дисбаланс в определении справедливости наказания. Ведь ужесточение наказания будет связано только с одним условием - наличием у лица, совершившего преступления звания, чина или награды. Таким образом, преступник, который ранее не приносил пользу обществу и, соответственно, не имеющий никаких поощрений и благодарностей, находится в более выгодном положении, чем тот человек, который имеет особые заслуги перед своим отечеством. В ст. 6 УК РФ установлено, что справедливость наказания определяется, исходя из соответствия совершенного деяния его общественной опасности, обстоятельствам его совершения и личности виновного. В данном случае положительные данные о личности являются одним из оснований (наряду с другими, указанными в законе) для применения к нему дополнительного наказания.

Таки образом, отмеченные тенденции назначения отдельных видов наказаний в РФ свидетельствуют о необходимости поиска взвешенного, законодательного решения.

\section{Список использованной литературы}

1. Кононыхин С. Ю. Проблемы эффективности некоторых основных видов наказаний при их реализации и взаимодействии со всей системой наказаний / С. Ю. Кононыхин // Вестник Тамбовского университета. - 2011. - № 11. - С. 438-440.

2. Ишегеев В. С. Современная система наказаний в России и пути повышения их эффективности / Ишегеев В. С. // Криминологический журнал Байкальского государственного университета экономики и права. - 2011. - № 4. - С. $16-20$.

3. Борисова Н. Ф. Соотношение ограничения свободы с условным осуждением / Н. Ф. Борисова // Уголовно-исполнительная система: право, экономика, управления. 2012. - № 2. - С. 16-19.

4. Становский М. Н. Назначение наказания / М. Н Становский. - СПБ.: Юридический центр Пресс, 1999. - 480 с.

5. Курс советского уголовного права. Часть Общая. Т. 3. Наказание/ под. ред. А. А. Пионтковского. М. : Наука, 1970. - 516 с.

\section{Baikal Research Journal}


6. Степашин В. М. Проблемы применения принудительных работ / В. М. Степашин // Вестник Омского университета. Серия «Право». — 2015. — № 4 (45). — С. 156-161

7. Непомнящая Т. В. Мера уголовного наказания: проблемы теории и практики / Т. В. Непомнящая. - М. : Юрлитинформ, 2012. - 293 с.

8. Нечаев А. Д., Усалев В. В. Проблемы создания учреждений, исполняющах наказание в виден ареста / А. Д. Нечаев, В. В. Усалев // Вопросы современнной юриспруденции. - 2015. - № 47. - С. 92-97.

9. Подройкина И. А. О перспективах ареста как уголовного наказания / И. А. Подройкина // Академический вестник Ростовского филиала российской таможенной академии. - 2015. - № 3 (20). - С. 65-69.

10. Савельева О. Ю. Принудительные работы как альтернатива лишению свободы: все «за» и «против» / О. Ю. Савельева // Вектор науки ТГУ. Серия: Юридические науки. 2015. - № 4 (23). - С. 34-35.

11. Купряченик О. С. Пути повышения эффективности уголовного наказания в виде принудительных работ / О. С. Купряченик // Общество: политика, экономика, право. 2016. - № 5. - С. 142-144.

12. Мирзорин М. Н. Актуальные проблемы введения принудительных работ: теоретико-правовые и практические вопросы / М. Н. Мирзорин // Вестник Таганрогского института управления и экономики. - 2016. - № 1. - С. 56-58.

\section{References}

1. Kononykhin S. Y. Problems of efficiency of certain main types of punishment in their implementation and interaction with the entire system of punishment. Vestnik Tambovskogo universiteta $=$ Bulletin of Tambov University, 2011, no. 11, pp. 438-440. (In Russian).

2. Ishegeev V. S. Modern penal system in Russia and ways to improving their effectiveness. Kriminologicheskii zhurnal Baikal'skogo gosudarstvennogo universiteta ekonomiki i pra$v a=$ Criminological Journal of Baikal State University of Economics and Law, 2011, no. 4, pp. 16-20. (In Russian).

3. Borisova N. F. Correlation of liberty restriction with probation. Ugolovno-ispolnitel'naya sistema: pravo, ekonomika, upravleniya = Penal Enforcement System: Law, Economics, Management, 2012, no. 2, pp.16 - 19. (In Russian).

4. Stanovskii M. N. Naznachenie nakazaniya [The purpose of punishment]. Saint Petersburg, Yuridicheskii tsentr Press Publ., 1999, 480 p.

5. Piontkovsky A. A. (ed.) Kurs sovetskogo ugolovnogo prava. Chast' Obshchaya. T. 3. Nakazanie [The Couse of Soviet Criminal Law. General Part. Vol. 3. Punishment]. Moscow, Nauka Publ., 1970. 516 p.

6. Stepashin V. M. Problems of application of forced labor Vestnik Omskogo universiteta. Seriya «Pravo»= Bulletin of Omsk University. Series «Law», 2015, no. 4 (45), pp. $156-161$. (In Russian).

7. Nepomnyashchaya T. V. Mera ugolovnogo nakazaniya: problemy teorii i praktiki [Measure of criminal punishment: problems of theory and practice]. Moscow,

Yurlitinform, 2012. $293 \mathrm{p}$.

8. Nechaev, A. D., Palev V. V. Problems of establishing institutions implementing punishment in form of arrest. Voprosy sovremennnoi yurisprudentsii = Issues of Modern Jurisprudence, 2015, no. 47, pp. 92-97. (In Russian).

9. Podroikina I. A. On prospects of arrest as a criminal punishment. Akademicheskii vestnik Rostovskogo filiala rossiiskoi tamozhennoi akademii = Academic Bulletin of Rostov Branch of Russian Customs Academy, 2015, no. 3 (20), pp. 65-69. (In Russian).

10. Savel'eva O. Yu. Forced labor as an alternative to imprisonment: the "pros» and «cons». Vektor nauki TGU. Seriya: Yuridicheskie nauki = Vector science TSU. Series: Law, 2015, no. 4 (23), pp. 34-35. (In Russian).

11. Kupryachenik O. S. Ways of increasing effectiveness of criminal punishment in the form of forced labor. Obshchestvo: politika, ekonomika, pravo = Society: Politics, Economics, Law, 2016, no. 5, pp. 14-44. (In Russian).

\section{Baikal Research Journal}


12. Mirzorin M. N. Topical problems of introducing forced labor: theoretical-legal and practical issues. Vestnik Taganrogskogo instituta upravleniya i ekonomiki = Bulletin of Taganrog Institute of Management and Economics, 2016, no. 1, pp. 56-58. (In Russian).

\section{Информация об авторах}

Корягина Светлана Анатольевна - кандидат юридических наук, доцент, доцент кафедры уголовного права, криминологии и уголовного процесса, Байкальский государственный университет, 664003, г. Иркутск, ул. Ленина, 11, koryagina.sveta@yandex.ru.

Лавыгина Ирина Васильевна - кандидат юридических наук, доцент, доцент кафедры уголовного права, криминологии и уголовного процесса, Байкальский государственный университет, 664003, г. Иркутск, ул. Ленина, 11, lavyginaiv@mail.ru.

\section{Authors}

Svetlana A. Koryagina - PhD in Law, Associate Professor, Chair of Criminal Law, Criminology and Criminal Procedure, Baikal State University, 11 Lenin St., 664003, Irkutsk, e-mail: koryagina.sveta@yandex.ru.

Irina V. Lavygina - PhD in Law, Associate Professor, Chair of Criminal Law, Criminology and Criminal Procedure, Baikal State University, 11 Lenin St., 664003, Irkutsk; e-mail: lavyginaiv@mail.ru.

\section{Для цитирования}

Корягина С.А., Лавыгина И.В. Современные тенденции назначения некоторых видов наказаний осужденным в Российской Федерации / С. А. Корягина, И. В. Лавыгина // Baikal Research Journal. - 2017. - T. 8 , № 3. - DOI : 10.17150/2411-6262.2017.8(3).19.

\section{For Citation}

Koryagina S. A., Lavygina I.V. Current trends the assignment of certain types of sentences convicted persons in the Russian Federation. Baikal Research Journal, 2017, vol. 8, no. 3. DOI: $10.17150 / 2411-6262.2017 .8(3) .19$. (In Russian).

\section{Baikal Research Journal}

